\title{
Predictors of human papillomavirus infection in women undergoing routine cervical cancer screening in Spain: the CLEOPATRE study
}

Esther Roura ${ }^{1}$, Thomas Iftner ${ }^{2}$, José Antonio Vidart ${ }^{3}$, Susanne Krüger Kjaer ${ }^{4,5}, \mathrm{~F}$ Xavier Bosch ${ }^{1}$, Nubia Muñoz , Santiago Palacios ${ }^{7}$, Maria San Martin Rodriguez ${ }^{8}$, Carmen Morillo ${ }^{8}$, Laurence Serradell ${ }^{9}$, Laurence Torcel-Pagnon 9 , Javier Cortes $^{10}$ and Xavier Castellsagué ${ }^{*}$, for the CLEOPATRE Spain Study Group

\begin{abstract}
Background: Human papillomavirus (HPV) is a sexually transmitted infection that may lead to development of precancerous and cancerous lesions of the cervix. The aim of the current study was to investigate sociodemographic, lifestyle, and medical factors for potential associations with cervical HPV infection in women undergoing cervical cancer screening in Spain.

Methods: The CLEOPATRE Spain study enrolled 3261 women aged 18-65 years attending cervical cancer screening across the 17 Autonomous Communities. Liquid-based cervical samples underwent cytological examination and HPV testing. HPV positivity was determined using the Hybrid Capture II assay, and HPV genotyping was conducted using the INNO-LiPA HPV Genotyping Extra assay. Multivariate logistic regression was used to identify putative risk factors for HPV infection.

Results: A lifetime number of two or more sexual partners, young age (18-25 years), a history of genital warts, and unmarried status were the strongest independent risk factors for HPV infection of any type. Living in an urban community, country of birth other than Spain, low level of education, and current smoking status were also independent risk factors for HPV infection. A weak inverse association between condom use and HPV infection was observed. Unlike monogamous women, women with two or more lifetime sexual partners showed a lower risk of infection if their current partner was circumcised (P for interaction, 0.005$)$ and a higher risk of infection if they were current smokers (P for interaction, 0.01).

Conclusion: This is the first large-scale, country-wide study exploring risk factors for cervical HPV infection in Spain. The data strongly indicate that variables related to sexual behavior are the main risk factors for HPV infection. In addition, in non-monogamous women, circumcision of the partner is associated with a reduced risk and smoking with an increased risk of HPV infection.
\end{abstract}

Keywords: HPV infection, Prevalence, Risk factors, Sexual behavior, Questionnaire, Spain

\footnotetext{
* Correspondence: xcastellsague@iconcologia.net

${ }^{1}$ Cancer Epidemiology Research Program, Institut Català d'Oncologia (ICO)-IDIBELL, CIBER-ESP, RTICC, L'Hospitalet de Llobregat, Barcelona, Catalonia, Spain

Full list of author information is available at the end of the article
} 


\section{Background}

Human papillomavirus (HPV) is one of the most common sexually transmitted infections worldwide. It is well established that HPV is the necessary cause of cervical cancer and its precancerous lesions. In addition, HPV has been associated with a wide range of other diseases including: genital warts; vulvar, vaginal, penile and anal cancers; head and neck cancers; and recurrent respiratory papillomatosis [1,2]. Most sexually active women will be infected with HPV during their lifetime [3]. While the majority of HPV infections are cleared within 2 years, persistent infections and the presence of risk factors that promote persistence may lead to the development of precancerous and cancerous lesions in a small fraction of women. HPV genotypes are classified as high-risk (HR) or low-risk (LR) based on their association with cervical cancer, HPV 16 being the type most commonly identified in this cancer [4].

Epidemiological studies conducted among women over the past decade have shown consistently that the prevalence of cervical HPV infection, particularly HR HPV types, is greatest among women below the age of 2530 years and lower in older women [5,6]. The increased infection rates among young women are attributable to higher exposure to HPV through multiple sexual partners. In contrast, older women tend to have fewer new partners and they may have developed some degree of immunity against HPV [7]. Other potential risk factors for cervical HPV infection include tobacco smoking [8], nulliparity [9], use of oral contraceptives [9], and recent new sexual partners [10]. Use of condoms may protect against cervical HPV infection [11].

Data on cervical HPV prevalence and determinants of HPV infection are sparse and limited in Spain. In a previous analysis of the CLEOPATRE Spain study, we reported the prevalence and type-specific distribution of cervical HPV infection among women aged 18-65 years attending cervical cancer screening in Spain [12]. In the current analysis we report on the association between socio-demographic, lifestyle and medical factors and the prevalence of cervical HPV infection. Only one previous epidemiological study has been carried out in the general female population of Spain to assess these risk factors [13]. Thus, the current analysis represents the first largescale, country-wide epidemiological study exploring risk factors for cervical HPV infection in Spain.

\section{Methods}

\section{Study participants and procedures}

The CLEOPATRE Spain study was a cross-sectional study conducted between June 2007 and May 2008 in 77 centers across the 17 Autonomous Communities in Spain. The study methods have been described previously in detail [12]. Briefly, women aged 18-65 years attending routine cervical cancer screening were recruited, excluding virgins and women who had a history of HPV-related cervical disease or HPV vaccination. All study participants provided written informed consent. Ethical clearance was obtained from the ethical committee of the Hospital Clínico San Carlos (Madrid, Spain).

Demographic and socio-economic data, information about sexual behavior, smoking habits, and medical history were collected after enrollment and recorded on a case report form. A liquid-based cytology (LBC) sample was collected from each participant. The LBC samples were sent to central laboratories for cytological diagnosis (Biomnis, R. Dachez, Paris, France), HPV detection (Biomnis, C. Ronsin, Ivry, France), and genotyping (Institute of Medical Virology, T. Iftner, University Hospital, Tübingen, Germany). HPV positivity was defined using the HPV DNA test, Hybrid Capture II (HC2; Digene Corporation, Gaithersburg, MD, USA). The HC2 assay uses two RNA probes, one to detect 13 HR types (16, $18,31,33,35,39,45,51,52,56,58,59$, and 68) and another one to detect 5 LR types $(6,11,42,43$, and 44$)$ in cervical samples [14]. Samples were considered to be HPV-positive if either of the two probes (low- and/or high-risk probes) were positive at a relative light unit coefficient (RLU/Co) of $\geq 1.0$, which corresponds to the HPV DNA threshold of $1.0 \mathrm{pg} / \mathrm{mL}$ recommended by the United States Food and Drug Administration (US FDA). HPV genotyping was determined in all study samples using the INNO-LiPA HPV Genotyping Extra assay (Innogenetics, Gent, Belgium). Only results of HPV genotyping for the HPV-HC2-positive women are shown. The INNO-LiPA test allows identification of 13 established HR HPV types (16, 18, 31, 33, 35, 39, 45, 51, $52,56,58,59$, and 66), 5 known or putative HR types (26, 53, 68, 73, and 82), 7 LR HPV types (6, 11, 40, 43, 44, 54, and 70), additional non-differentiated HPV types, and types with undefined risk (74 and 69/71). Automated results were confirmed with blinded manual readings undertaken by experienced laboratory personnel.

\section{Risk factor analysis}

The evaluation of potential risk factors included age, type of community (rural, suburban or urban based on population size of municipality), country of birth, marital status, level of education, professional status, smoking status (including duration and intensity), pregnancies, contraceptive methods, lifetime number of sexual partners, age at first sexual intercourse, time since first sexual intercourse, history of cervical lesions, history of sexually transmitted infections (STIs), current partner's history of STIs in the last 12 months, current partner's circumcision status, and immune status.

The association between cervical HPV infection and potential risk factors was tested by multivariate analysis, 
which involved construction of an adjusted logistic regression model using stepwise regression with forward selection. Beginning with a basic model adjusted for age and Autonomous Community, the variables for the potential risk factors were added one at a time into the model to evaluate their association with cervical HPV infection, and those that showed a statistically significant association ( $\mathrm{P}$-value $<0.10)$ were retained in the final model as adjusting variables.

Adjusted models were also constructed to evaluate the association between potential risk factors and HR HPV, LR HPV, HPV 16, and single and multiple HPV infections. Analyses were conducted to explore multiplicative interactions between lifetime number of sexual partners and other potential risk factors for cervical HPV infection. In addition, an adjusted model was constructed to assess risk factors for HPV positivity among young women aged 18-25 years.

Analyses were performed using the $\mathrm{R}$ programing language ( $\mathrm{R}$ Development Core Team, 2005, http:// www.r-project.org).

\section{Results}

\section{Study participants}

A total of 7252 women were initially registered in the recruitment logs at the participating sites. Of those, 4 206 were eligible and 3261 were finally enrolled in the study. The participation rate was $77.5 \%$ (3 261/4 206). Reasons for non-participation among eligible women were: refusal (13.2\%), and other reasons such as logistic problems or menstruation (9.3\%). The characteristics of study participants have been described previously [12]. In brief, $91.3 \%$ of the women were born in Spain, 77.2\% lived in an urban area ( $\geq 10000$ inhabitants), $39.7 \%$ were single, $33.0 \%$ had a university/college education, $25.5 \%$ were students, $35.6 \%$ were current smokers, and 19.5\% reported having had four or more lifetime sexual partners. There was a planned oversampling of young women aged $\leq 25$ years (49.6\%) compared with the proportion of this age group in the overall female population of Spain (18.0\%).

\section{Prevalence of HPV}

HC2 results were available for 3155 (96.7\%) women [12]. A total of 608 (19.3\%) women were HPV-positive based on the HC2 assay, 527 of whom $(86.7 \%)$ were infected with one or more HR types (with or without concomitant LR HPV infection). LiPA results were available for $606 \mathrm{HC} 2$-positive samples (497 LiPA positive and 109 LiPA negative). Single and multiple HPV infections were detected in 49.2\% (298/606) and 32.8\% (199/ 606) of these samples, respectively.

\section{Risk factor analysis}

\section{Risk factors for any HPV infection}

In the basic model adjusted for age and Autonomous Community, the following characteristics were positively and statistically significantly associated with cervical HPV infection: young age; living in an urban community; country of birth other than Spain; unmarried status; current smoker; more than one lifetime sexual partner; young age at first sexual intercourse (with a statistically significant trend); more years elapsed since first intercourse (with a statistically significant trend); and a history of cervical lesions, genital warts or other STIs (Table 1). There was also a weak and statistically borderline inverse association between systematic use of condoms in the last 12 months, meaning use of condom in $90-100 \%$ of all sexual relationships that occurred in the last year, and cervical HPV infection. No associations were identified between cervical HPV infection and number of pregnancies, use of oral contraceptives, ever use of condoms or a current sexual partner who was circumcised or with STIs in the last 12 months. Other variables, including type of medical practice and setting, professional status, duration and intensity of smoking, use of an intrauterine device, and immune status, were also assessed but no associations with HPV infection were observed (data not shown).

In the final adjusted model, variables that remained statistically significant were: age $18-25$ years; living in an urban community; country of birth other than Spain; unmarried status; lower level of educational attainment (with a statistically significant trend); current smoker; more than one lifetime sexual partner; and a history of genital warts (Table 2). A high lifetime number of sexual partners, a history of genital warts, and unmarried status were the risk factors most strongly associated with cervical HPV infection. Notably, women who had four or more sexual partners had a 4-fold higher risk of being HPV-positive than women who had only one sexual partner.

It is interesting to note that the pattern of association with age at first intercourse in the adjusted model was opposite to that found in the basic model. While in the crude analysis young age at first intercourse was associated with increased HPV prevalence, in the fully adjusted model this effect was reversed and young age at first intercourse was associated with reduced HPV prevalence ( $\mathrm{P}$ for trend $=0.003$ ) (Table 2 ). To explore these associations further, we performed stratified analyses by levels of lifetime number of sexual partners and levels of age at first sexual intercourse (Figure 1). As shown in Figure 1a, HPV prevalence was not associated with age at first intercourse within each category of number of sexual partners. In contrast, Figure $1 \mathrm{~b}$ shows that HPV prevalence was strongly associated with lifetime number 
Table 1 Prevalence of cervical human papillomavirus infection and crude associations between infection and selected subjects' characteristics

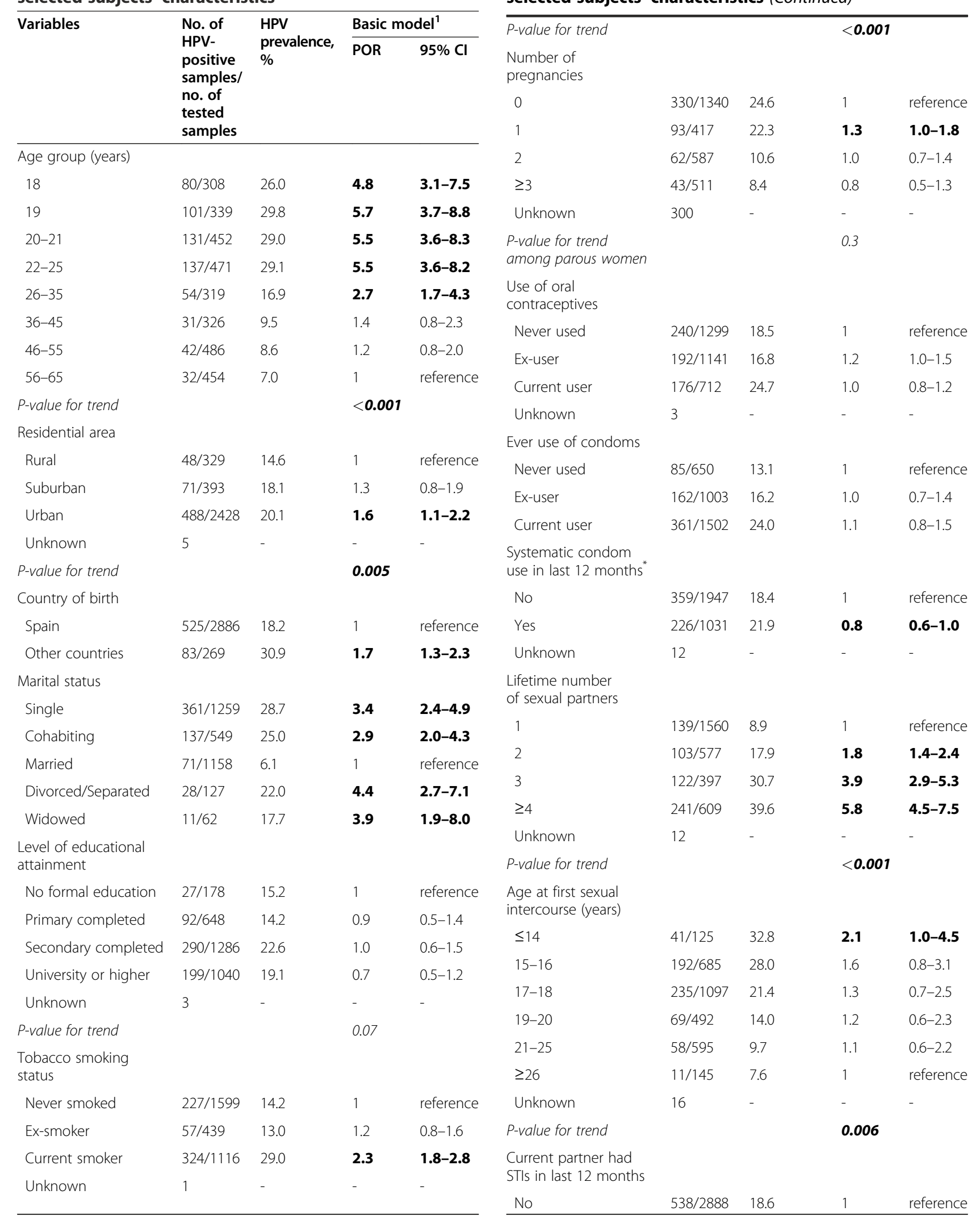

Table 1 Prevalence of cervical human papillomavirus infection and crude associations between infection and selected subjects' characteristics (Continued)

$P$-value for trend

Number of

pregnancies

1.3

Age group (years)

Page 4 of 13 
Table 1 Prevalence of cervical human papillomavirus infection and crude associations between infection and selected subjects' characteristics (Continued)

\begin{tabular}{lllll}
\hline Yes & $9 / 38$ & 23.7 & 1.1 & $0.5-2.4$ \\
Unknown & 229 & - & - & - \\
Current partner & & & & \\
circumcised & & & & \\
No & $432 / 2366$ & 18.3 & 1 & reference \\
Yes & $60 / 369$ & 16.3 & 0.9 & $0.6-1.2$ \\
Unknown & 420 & - & - & - \\
Previous cervical & & & & \\
lesions & & & & \\
No & $559 / 2952$ & 18.9 & 1 & reference \\
Yes & $36 / 178$ & 20.2 & $\mathbf{1 . 7}$ & $\mathbf{1 . 1 - 2 . 5}$ \\
Unknown & 25 & - & - & - \\
History of genital & & & & \\
warts & & & & \\
No & $555 / 3061$ & 18.1 & 1 & reference \\
Yes & $50 / 87$ & 57.5 & $\mathbf{4 . 8}$ & $\mathbf{3 . 1}-\mathbf{7 . 6}$ \\
Unknown & 7 & - & - & - \\
History of other STIs & & & & \\
No & $579 / 3054$ & 19.0 & 1 & reference \\
Yes & $23 / 87$ & 26.4 & $\mathbf{1 . 7}$ & $\mathbf{1 . 0 - 2 . 8}$ \\
Unknown & 14 & - & - & - \\
\hline
\end{tabular}

$\mathrm{HPV}$, human papillomavirus; POR, prevalence odds ratio; $\mathrm{Cl}$, confidence interval; STI, sexually transmitted infection.

'Basic model: adjusted for age and Autonomous Community.

*Among women with a sexual partner in the last 12 months.

Bold font indicates a significant effect $(P<0.05)$.

of sexual partners within each category of age at first intercourse $(P<0.001$ for each age stratum). These stratified analyses show that HPV prevalence is more strongly associated with lifetime number of sexual partners than with age at first sexual intercourse. A similar effect was obtained when evaluating time since first sexual intercourse instead of age at first intercourse.

\section{Interaction between lifetime number of sexual partners,} male circumcision, and smoking status

Interaction analyses showed that having a current partner who was circumcised had a significant protective effect against cervical HPV infection in women reporting two or more lifetime sexual partners but not in monogamous women $(P$ for interaction $=0.005)$ (Table 3$)$. A synergistic interaction with cervical HPV infection was also observed between smoking and having two or more lifetime sexual partners. Thus, the risk of infection almost doubled in women reporting two or more lifetime sexual partners if they were current smokers, whereas in monogamous women current smokers showed little increase in risk compared with non-smokers $(P$ for interaction $=0.01)$.
Table 2 Multivariate analyses of the association between cervical human papillomavirus infection and selected subjects' characteristics

\begin{tabular}{|c|c|c|c|}
\hline & \multirow{2}{*}{$\begin{array}{l}\text { No. of } \\
\text { tested } \\
\text { samples }\end{array}$} & \multicolumn{2}{|c|}{ Adjusted model $^{1}$} \\
\hline & & POR & $95 \% \mathrm{Cl}$ \\
\hline \multicolumn{4}{|c|}{ Age group (years) } \\
\hline 18 & 308 & 1.7 & $1.1-3.1$ \\
\hline 19 & 339 & 2.2 & $1.4-3.7$ \\
\hline $20-21$ & 452 & 2.1 & $1.3-3.4$ \\
\hline $22-25$ & 471 & 1.9 & $1.2-3.2$ \\
\hline $26-35$ & 319 & 1.1 & $0.7-1.9$ \\
\hline $26-45$ & 326 & 0.7 & $0.4-1.2$ \\
\hline $46-55$ & 486 & 0.8 & $0.5-1.3$ \\
\hline $56-65$ & 454 & 1 & reference \\
\hline$P$-value $f_{c}$ & & \multicolumn{2}{|c|}{$<0.001$} \\
\hline
\end{tabular}

Residential area

Rural

Suburban

Urban

Unknown

$P$-value for trend

Country of birth

Spain

2886

reference

Other countries

269

1.7

1.3-2.4

Marital status

Married

1158

Single

1259

1

reference

1.3

$0.8-2.1$

1.5

1.0-2.2

Cohabiting

549

Divorced/Separated

Widowed

$$
62
$$

0.03

Level of education

attainment

No formal education $\quad 178$

Primary completed

Secondary completed

University or higher

$$
1040
$$

Unknown

\section{3}

P-value for trend

reference

Tobacco smoking status

Never smoked

Ex-smoker

Current smoker

Unknown

$P$-value for trend

reference

$0.5-1.5$

0.5-1.4

$0.4-1.1$

Ever use of condoms

Never used

650

reference 
Table 2 Multivariate analyses of the association between cervical human papillomavirus infection and selected subjects' characteristics (Continued)

\begin{tabular}{|c|c|c|c|}
\hline Ex or current user & 2505 & 0.9 & $0.6-1.1$ \\
\hline \multicolumn{4}{|c|}{$\begin{array}{l}\text { Systematic condom } \\
\text { use in last } 12 \text { months }\end{array}$} \\
\hline No & 1947 & 1 & reference \\
\hline Yes & 1031 & 0.8 & $0.6-1.0$ \\
\hline Unknown & 12 & - & - \\
\hline \multicolumn{4}{|l|}{$\begin{array}{l}\text { Lifetime number of } \\
\text { sexual partners }\end{array}$} \\
\hline 1 & 1560 & 1 & reference \\
\hline 2 & 577 & 1.5 & $1.1-2.1$ \\
\hline 3 & 397 & 3.3 & $2.5-4.5$ \\
\hline$\geq 4$ & 609 & 4.1 & $3.1-5.4$ \\
\hline Unknown & 12 & - & - \\
\hline P-value for trend & & $<0.001$ & \\
\hline \multicolumn{4}{|l|}{$\begin{array}{l}\text { Age at first sexual } \\
\text { intercourse (years) }\end{array}$} \\
\hline$\leq 14$ & 125 & 0.5 & $0.2-1.2$ \\
\hline $15-16$ & 685 & 0.6 & $0.3-1.2$ \\
\hline $17-18$ & 1097 & 0.7 & $0.3-1.4$ \\
\hline $19-20$ & 492 & 0.8 & $0.4-1.6$ \\
\hline $21-25$ & 595 & 1.0 & $0.5-2.1$ \\
\hline$\geq 26$ & 145 & 1 & reference \\
\hline Unknown & 16 & - & - \\
\hline P-value for trend & & 0.003 & \\
\hline \multicolumn{4}{|l|}{$\begin{array}{l}\text { Current partner } \\
\text { circumcised }\end{array}$} \\
\hline No & 2366 & 1 & reference \\
\hline Yes & 369 & 0.8 & $0.6-1.1$ \\
\hline Unknown & 420 & - & - \\
\hline \multicolumn{4}{|c|}{ History of genital warts } \\
\hline No & 3061 & 1 & reference \\
\hline Yes & 87 & 3.2 & $2.0-5.2$ \\
\hline Unknown & 7 & - & - \\
\hline
\end{tabular}

POR, prevalence odds ratio; $\mathrm{Cl}$, confidence interval.

${ }^{1}$ Adjusted model: adjusted for age, Autonomous Community, country of birth marital status, level of education, smoking habits, lifetime number of sexual partners, and history of genital warts.

*Among women with a sexual partner in the last 12 months.

Bold font indicates a significant effect $(P<0.05)$

No other statistically significant interactions with lifetime number of sexual partners were found.

\section{Risk factors for HPV infection in young women}

We examined the potential risk factors associated with HPV infection among young women aged $\leq 25$ years. In the adjusted model, the lifetime number of sexual partners, a history of genital warts, a country of birth other than Spain, and current smoking status were identified as the most important risk factors for cervical HPV infection (data not shown). Young age at first intercourse was associated with decreased HPV prevalence $(P$ for trend $=0.006$ ). Accordingly, increasing time since first sexual intercourse was also inversely associated with HPV infection $(P$ for trend $=0.06)$

\section{Risk factors for HR versus LR HPV infections and for HPV 16 infections}

We explored whether the determinants for HR HPV infection differed from those for LR infection by carrying out a stratified analysis (Table 4). The risk factors for HR infections (Table 4) were the same as those for any HPV infection (Table 2). In contrast, the determinants for LR HPV infection were: history of genital warts, increasing lifetime number of sexual partners, being single, and (inversely but weakly) ever use of condoms (Table 4). We also compared the risk factors for HR versus LR HPV infections by modeling infected women only. The following factors were positively associated with $\mathrm{HR}$ as compared to LR infection: birth in countries other than Spain, ever use of condoms, and a history of previous cervical lesions (data not shown).

Determinants associated with HPV 16 infection, compared with HPV-negative women, were also evaluated. Women of young age, smokers, and women with more than two lifetime sexual partners had an increased risk of HPV 16 infection (data not shown).

\section{Risk factors for single versus multiple HPV infections}

In a stratified adjusted model, the same variables as those identified in the adjusted model for any HPV infection (Table 2) were independently associated with single or multiple HPV infections (Table 5), except for residential area. Furthermore, ever use of condoms had a borderline protective effect against single HPV infection but not against multiple infection. Regression models comparing potential risk factors for multiple versus single HPV infections showed that women with more than two lifetime sexual partners were more likely to have multiple than single HPV infections (data not shown).

\section{Discussion}

This is the first large-scale, country-wide study in Spain to evaluate potential risk factors for cervical HPV infection. In addition to young age, a lifetime number of two or more sexual partners, a history of genital warts, and being unmarried were the strongest risk factors for cervical HPV infection among women aged 18-65 years attending routine cervical cancer screening across Spain. Living in an urban community, country of birth other than Spain, low level of education, and current smoking were also identified as independent risk factors for 
(a)



(b)



Figure 1 Prevalence odds ratios for human papillomavirus*. (a) The association between cervical HPV infection and age at first sexual intercourse stratified by lifetime number of sexual partners. Reference group: $\geq 21$ years of age at first sexual intercourse. (b) The association between cervical HPV infection and lifetime number of sexual partners stratified by age at first sexual intercourse. Reference group: 1 sexual partner. $P<0.001$ for association for each age stratum. *Model adjusted for age, Autonomous Community, country of birth, marital status, level of education, smoking habits, and history of genital warts.

cervical HPV infection. Condom use provided a borderline protective effect against HPV infection.

Our results agree with those of a previous epidemiological study in the general female population of Spain $(\mathrm{N}=973)$ conducted in 2003 by de Sanjose et al., which found the following independent risk factors of HPV infection: overseas birth, divorce, more than one sexual partner, and smoking marijuana or related products. Use of condoms with a regular partner was found to be protective against HPV, but with a borderline effect [13].

As in other studies [7,10,11,13], an increased lifetime number of sexual partners was the most consistent risk factor for cervical HPV infection identified in our study. In contrast, age at first sexual intercourse was not identified as an independent risk factor in the multivariate

Table 3 Association between male circumcision, smoking, and cervical human papillomavirus infection by number of sexual partners

\begin{tabular}{|c|c|c|c|}
\hline & \multicolumn{2}{|c|}{$\begin{array}{l}\text { HPV infection } \\
\text { POR }(95 \% \mathrm{CI})\end{array}$} & \multirow[t]{2}{*}{$\begin{array}{l}P \text {-value of } \\
\text { interaction* }\end{array}$} \\
\hline & $\begin{array}{l}1 \text { sexual } \\
\text { partner }\end{array}$ & $\begin{array}{l}\geq 2 \text { sexual } \\
\text { partners }\end{array}$ & \\
\hline $\begin{array}{l}\text { Current partner } \\
\text { circumcised }\end{array}$ & & & 0.005 \\
\hline No (reference) & 1.0 & 1.0 & \\
\hline Yes & $1.6(1.0-2.7)$ & $0.6(0.4-0.9)$ & \\
\hline $\begin{array}{l}\text { Tobacco smoking } \\
\text { status }\end{array}$ & & & 0.01 \\
\hline Never/ex-smoker (reference) & 1.0 & 1.0 & \\
\hline Current smoker & $1.1(0.7-1.7)$ & $2.0(1.6-2.5)$ & \\
\hline
\end{tabular}

POR, prevalence odds ratio; $\mathrm{Cl}$, confidence interval.

*Log-Likelihood test.

Model adjusted for age, Autonomous Community, country of birth, marital status, level of education, smoking habits, lifetime number of sexual partners, and history of genital warts.

Bold font indicates a significant effect $(P<0.05)$. analysis, in accordance with some previous studies $[7,10,13]$. In our study, young age at first intercourse increased the risk of HPV infection in the unadjusted model but in the adjusted one the effect was reversed. The inclusion of number of sexual partners in the adjusted model explained this change, indicating reverse co-linearity between the two variables. Our further stratified analyses, as shown in Figure 1, strongly suggested that the key determinant of cervical HPV infection is the number of sexual partners the woman had had and not the age at first sexual intercourse. These findings are in agreement with other studies suggesting that age at sexual debut is a likely predictor of lifetime number of sexual partners and not a factor independently associated with cervical HPV infection [15,16]. A similar effect was observed when time since first sexual intercourse was assessed rather than age at first sexual intercourse.

Country of birth other than Spain was identified as an independent risk factor for cervical HPV infection, a finding that was reported in a previous, smaller study conducted in Spain [13]. In our study, most women born outside Spain were immigrants from Latin America. The HPV prevalence in these countries is higher than that in Spain $[17,18]$. The increased prevalence of HPV among immigrant women compared with women born in Spain may be related to well-known differences in sexual behavior in both men and women.

In agreement with the pooled analysis of the International Agency for Research on Cancer (IARC) on smoking and HPV prevalence [8], we identified current smoking status as an independent risk factor for cervical HPV infection. A large population-based study conducted in women from Costa Rica found a positive association between smoking status and HPV 16, an association that was also found to be statistically significant in our study [10]. Intensity of smoking was 
Table 4 Multivariate analyses of the association between high- and low-risk human papillomavirus infections and selected subjects' characteristics



Table 4 Multivariate analyses of the association between high- and low-risk human papillomavirus infections and selected subjects' characteristics (Continued) 
Table 4 Multivariate analyses of the association between high- and low-risk human papillomavirus infections and selected subjects' characteristics (Continued)

\begin{tabular}{lllllll}
\hline No & 2311 & 1 & reference & 1989 & 1 & reference \\
Yes & 359 & 0.7 & $0.5-1.0$ & 319 & 1.2 & $0.6-2.4$ \\
Unknown & 404 & - & - & 320 & - & - \\
History of & & & & & & \\
genital warts & & & & & & \\
No & 2991 & 1 & reference & 2576 & 1 & reference \\
Yes & 78 & $\mathbf{2 . 9}$ & $\mathbf{1 . 7 - 4 . 9}$ & 46 & $\mathbf{6 . 6}$ & $\mathbf{2 . 8}-\mathbf{1 5 . 4}$ \\
Unknown & 5 & - & - & 6 & - & -
\end{tabular}

HPV, human papillomavirus; HR, high-risk; LR, low-risk; POR, prevalence odds ratio; $\mathrm{Cl}$, confidence interval.

${ }^{1}$ Adjusted model: adjusted for age, Autonomous Community, country of birth, marital status, level of education, smoking habits, lifetime number of sexual partners, and history of genital warts.

Among women with a sexual partner in the last 12 months

Bold font indicates a significant effect $(P<0.05)$.

identified as another predictor of HPV infection in the IARC analysis, but these data were not statistically significant in our adjusted model. An association between smoking and cervical HPV infection is difficult to assess because of the strong confounding effect of sexual behavior. To address this we performed further logistic regression analyses to formally test for the interaction between smoking and number of sexual partners, and found a statistically significant interaction between the two risk factors (Table 3). Smoking was associated with a two-fold increased prevalence of cervical HPV in women with multiple sexual partners but not among monogamous women. In contrast, in the IARC study a significant relationship of smoking intensity was seen only among women who reported one sexual partner, but not among women reporting more partners. A possible explanation for this interaction is that among women with a high exposure to HPV (those with multiple partners) the risk of infection is much increased if they are concomitantly exposed to smoking. Conversely, smoking in the absence of high exposure to HPV is not as relevant in determining the risk of HPV infection. Some studies have documented that in the presence of $\mathrm{HPV}$, tobacco products may reduce local immunological responses, which might facilitate HPV acquisition, reduce HPV clearance, or increase HPV persistence, thus increasing the overall HPV prevalence $[19,20]$.

Condom use was found to be inversely but weakly associated with cervical HPV infection. The protective effect of condom use against HPV infection is controversial in the literature. Whereas some previous studies have reported a weak association with HPV infection $[10,11,13]$, others have not [7]. Taking into account the weak magnitude of the associations found overall and in the subgroup analyses performed in our study, the beneficial effect of condom use on HPV prevalence is probably small.

Although male circumcision was not identified as a predictor of cervical HPV infection in our study, interaction analyses showed a protective effect among women at increased risk of HPV infection (i.e. women who had more sexual partners). Previous studies have shown that circumcised men are less likely to have penile HPV infection than uncircumcised men and that male circumcision infers a protective effect in female sexual partners for cervical HPV infections as well as for cervical cancer $[21,22]$.

A strength of this study is that the age-stratified sampling strategy used within each of the Autonomous Communities of Spain (except Ceuta and Melilla) provided a good demographic representation of the agespecific female population attending cervical cancer screening across the country. However, a potential limitation is that women were selected from opportunistic cervical cancer screening programs, which may have resulted in the preferential recruitment of healthconscious or healthier women. This potential overrepresentation of "healthy" women could underestimate the true prevalence of risk factors related to cervical HPV infection, such as tobacco smoking, high number of sexual partners or having never used a condom. The potential effect of this would be an underestimation of the true effects related to these risk factors. In order to assess potential selection bias, the distribution of key socio-demographic and lifestyle characteristics of women included in the CLEOPATRE study was compared with that of the general female population of Spain using public data such as marital status, parity, use of contraceptive methods, and number of sexual partners among others. We ascertained that the study population was indeed representative of the general female population in Spain (data not shown). As with any other crosssectional design, there is a risk of reporting bias, particularly in relation to variables that address aspects of sexual behavior, such as "age at first sexual intercourse," "lifetime number of sexual partners," and "partner's circumcision status." Other studies have noted also the possibility of this non-differential misclassification related to sexual behavior [7]. It is well known that nondifferential misclassification cannot inflate true effects; instead, it would shift the observed association towards the null value.

Another limitation of our study is that only $80 \%$ of the HC2-positive samples were positive by LiPA, a much more sensitive assay than $\mathrm{HC}$. This apparently low performance of the LiPA assay may be explained by the inherent differences between the two assays. Although the HC2 assay is designed to detect $18 \mathrm{HPV}$ types (including the low-risk types), several studies have noted that the 
Table 5 Multivariate analyses of the association between single and multiple human papillomavirus infections and selected subjects' characteristics

\begin{tabular}{|c|c|c|c|c|c|c|}
\hline & \multicolumn{3}{|c|}{$\begin{array}{l}\text { Single infection } \\
\text { vs. negative } \\
(\mathrm{n}=2845)\end{array}$} & \multicolumn{3}{|c|}{$\begin{array}{l}\text { Multiple infection } \\
\text { vs. negative } \\
(\mathrm{n}=2746)\end{array}$} \\
\hline & \multirow{2}{*}{$\begin{array}{l}\text { No. } \\
\text { tested }\end{array}$} & \multicolumn{2}{|c|}{ Adjusted model $^{1}$} & \multirow{2}{*}{$\begin{array}{l}\text { No. } \\
\text { tested }\end{array}$} & \multicolumn{2}{|c|}{ Adjusted model $^{1}$} \\
\hline & & POR & $95 \% \mathrm{Cl}$ & & POR & $95 \% \mathrm{Cl}$ \\
\hline \multicolumn{7}{|l|}{ Age group (years) } \\
\hline 18 & 268 & 3.1 & $1.4-6.8$ & 257 & 3.7 & $1.2-11.8$ \\
\hline 19 & 287 & 3.5 & $1.6-7.5$ & 273 & 4.1 & $1.3-12.9$ \\
\hline $20-21$ & 382 & 3.1 & $1.5-6.5$ & 369 & 4.0 & $1.3-12.5$ \\
\hline $22-25$ & 401 & 3.1 & $1.5-6.4$ & 387 & 3.8 & $1.2-11.7$ \\
\hline $26-35$ & 301 & 2.4 & $1.1-4.9$ & 279 & 1.5 & $0.4-4.9$ \\
\hline $36-45$ & 309 & 0.9 & $0.4-2.1$ & 304 & 1.4 & $0.4-5.0$ \\
\hline $46-55$ & 464 & 1.1 & $0.5-2.5$ & 451 & 0.97 & $0.3-3.5$ \\
\hline $56-65$ & 433 & 1 & reference & 426 & 1 & reference \\
\hline$P$-value for trend & & $<0.00$ & & & 0.001 & \\
\hline \multicolumn{7}{|l|}{ Residential area } \\
\hline Rural & 305 & 1 & reference & 301 & 1 & reference \\
\hline Suburban & 359 & 1.3 & $0.7-2.4$ & 344 & 0.9 & $0.4-2.0$ \\
\hline Urban & 2176 & 1.4 & $0.9-2.4$ & 2097 & 1.0 & $0.6-1.9$ \\
\hline Unknown & 5 & - & - & 4 & - & - \\
\hline$P$-value for trend & & 0.2 & & & 0.8 & \\
\hline \multicolumn{7}{|l|}{ Country of birth } \\
\hline Spain & 2616 & 1 & reference & 2528 & 1 & reference \\
\hline Other countries & 229 & 2.0 & $1.3-3.0$ & 218 & 2.2 & $1.3-3.5$ \\
\hline \multicolumn{7}{|l|}{ Marital status } \\
\hline Married & 1120 & 1 & reference & 1097 & 1 & reference \\
\hline Single & 1073 & 2.4 & $1.5-4.1$ & 1034 & 3.2 & $1.4-7.2$ \\
\hline Cohabiting & 483 & 2.1 & $1.3-3.6$ & 452 & 2.0 & $0.9-4.7$ \\
\hline $\begin{array}{l}\text { Divorced/ } \\
\text { Separated }\end{array}$ & 114 & 2.6 & $1.3-5.2$ & 110 & 5.4 & $2.1-14.2$ \\
\hline Widowed & 55 & 3.5 & $1.1-11.0$ & 53 & 7.0 & 1.3-37.9 \\
\hline \multicolumn{7}{|c|}{ Level of education attainment } \\
\hline $\begin{array}{l}\text { No formal } \\
\text { education }\end{array}$ & 160 & 1 & reference & 162 & 1 & reference \\
\hline $\begin{array}{l}\text { Primary } \\
\text { completed }\end{array}$ & 600 & 1.3 & $0.6-3.0$ & 584 & 0.7 & $0.3-1.5$ \\
\hline $\begin{array}{l}\text { Secondary } \\
\text { completed }\end{array}$ & 1139 & 1.3 & $0.6-2.8$ & 1095 & 0.6 & $0.3-1.4$ \\
\hline $\begin{array}{l}\text { University or } \\
\text { higher }\end{array}$ & 943 & 1.1 & $0.5-2.3$ & 902 & 0.5 & $0.2-1.0$ \\
\hline Unknown & 3 & - & - & 3 & - & - \\
\hline$P$-value for trend & & 0.4 & & & 0.03 & \\
\hline \multicolumn{7}{|c|}{ Tobacco smoking status } \\
\hline Never smoked & 1478 & 1 & reference & 1438 & 1 & reference \\
\hline Ex-smoker & 412 & 1.1 & $0.7-1.7$ & 398 & 1.0 & $0.5-1.8$ \\
\hline Current smoker & 954 & 1.7 & $1.3-2.3$ & 909 & 1.6 & $1.1-2.4$ \\
\hline
\end{tabular}

Table 5 Multivariate analyses of the association between single and multiple human papillomavirus infections and selected subjects' characteristics (Continued)

\begin{tabular}{|c|c|c|c|c|c|c|}
\hline Unknown & 1 & - & - & 1 & - & - \\
\hline P-value for trenc & & $<0.001$ & & & 0.005 & \\
\hline \multicolumn{7}{|c|}{ Ever use of condoms } \\
\hline Never used & 612 & 1 & reference & 582 & 1 & reference \\
\hline $\begin{array}{l}\text { Ex or } \\
\text { current user }\end{array}$ & 2233 & 0.7 & $0.4-1.0$ & 2164 & 1.1 & $0.6-1.9$ \\
\hline \multicolumn{7}{|c|}{ Systematic condom use in last 12 months $^{*}$} \\
\hline No & 1761 & 1 & reference & 1707 & 1 & reference \\
\hline Yes & 921 & 0.8 & $0.6-1.1$ & 880 & 0.7 & $0.5-1.0$ \\
\hline Unknown & 12 & - & - & 11 & - & - \\
\hline
\end{tabular}

$\begin{array}{llllll}1 & 1487 & 1 & \text { reference } & 1447 & 1\end{array}$ reference

$\begin{array}{lllllll}2 & 528 & \mathbf{1 . 6} & \mathbf{1 . 1}-\mathbf{2 . 4} & 504 & \mathbf{2 . 3} & \mathbf{1 . 3}-\mathbf{3 . 9}\end{array}$

$\begin{array}{lllllll}3 & 337 & \mathbf{3 . 4} & \mathbf{2 . 3}-\mathbf{5 . 0} & 319 & \mathbf{6 . 0} & \mathbf{3 . 5}-\mathbf{1 0 . 2}\end{array}$

$\begin{array}{lllllll}\geq 4 & 482 & \mathbf{3 . 7} & \mathbf{2 . 6}-\mathbf{5 . 4} & 466 & \mathbf{8 . 1} & \mathbf{5 . 0}-\mathbf{1 3 . 3}\end{array}$

Unknown $11 \quad \ldots \quad \ldots \quad 10$

p-value for trend $\quad<\mathbf{0 . 0 0 1}<0.001$

Age at first sexual intercourse (years)

$\begin{array}{lllllll}\leq 14 & 104 & 0.7 & 0.2-2.3 & 100 & 0.4 & 0.1-2.4 \\ 15-16 & 589 & 0.8 & 0.3-2.5 & 567 & 0.6 & 0.1-2.8 \\ 17-18 & 973 & 0.9 & 0.3-2.6 & 941 & 0.7 & 0.1-3.3 \\ 19-20 & 459 & 1.1 & 0.3-3.2 & 440 & 0.8 & 0.2-3.7 \\ 21-25 & 567 & 1.4 & 0.5-4.2 & 548 & 1.0 & 0.2-4.8 \\ \geq 26 & 138 & 1 & \text { reference } & 136 & 1 & \text { reference }\end{array}$

Unknown 15 -

$\begin{array}{ccc}P \text {-value for trend } & \mathbf{0 . 0 3} & 0.07\end{array}$

Current partner circumcised

$\begin{array}{lllllll}\text { No } & 2138 & 1 & \text { reference } & 2079 & 1 & \text { reference } \\ \text { Yes } & 343 & 0.9 & 0.6-1.4 & 327 & 0.7 & 0.4-1.3 \\ \text { Unknown } & 364 & - & - & 340 & - & -\end{array}$

History of genital warts

$\begin{array}{lllllr}\text { No } & 2780 & 1 & \text { reference } & 2684 & 1\end{array}$

$\begin{array}{lllllll}\text { Yes } & 59 & \mathbf{2 . 8} & \mathbf{1 . 5}-\mathbf{5 . 1} & 58 & \mathbf{4 . 4} & \mathbf{2 . 3}-\mathbf{8 . 8}\end{array}$

$\begin{array}{llllll}\text { Unknown } & 6 & - & - & 4\end{array}$

$\mathrm{POR}$, prevalence odds ratio; $\mathrm{Cl}$, confidence interval.

${ }^{1}$ Adjusted model: adjusted for age, Autonomous Community, country of birth marital status, level of education, smoking habits, lifetime number of sexual partners, and history of genital warts.

Among women with a sexual partner in the last 12 months.

Bold font indicates a significant effect $(P<0.05)$.

HC2 HR probe mix may cross-react with other HPV types that are not represented in the mix [23-25]. Data on the cross-reactivity of the low-risk probe are not available, but it can be assumed that cross-reactivity also takes place with that probe. In contrast, in the LiPA test (which is designed to detect $27 \mathrm{HPV}$ genotypes by 
identification of highly specific HPV DNA sequences), cross-reactivity with other HPV types has not been observed. It is thus conceivable that HPV types detected by $\mathrm{HC} 2$ through cross-hybridization are not detectable with the LiPA assay. The HR probe and the LR probe, with an unknown extent of cross-reactivity, were both used in the present study, and this may explain the observed relatively low sensitivity of the LiPA assay. When comparing the two methods, a Kappa value of 0.67 (95\% CI, 0.64-0.70) was found, which could be interpreted as being acceptable.

\section{Conclusion}

This analysis of the CLEOPATRE Spain study has identified several socio-demographic, lifestyle, and medical factors associated with cervical HPV infection. Cervical HPV is a highly prevalent sexually transmitted infection in women in Spain, particularly among those under 30 years of age in whom the prevalence approaches $30 \%$. In addition to young age, increasing number of lifetime sexual partners and a history of genital warts were identified as key risk factors for cervical HPV infection, particularly for HR HPV, reinforcing knowledge that cervical HPV infection is acquired early in a woman's sexual life. Living in an urban community, country of birth other than Spain, low level of education, and current smoking were also identified as independent risk factors for HPV infection. A weak inverse association between condom use and HPV infection was also observed. In non-monogamous women, circumcision of the partner was associated with a reduced risk of HPV infection and smoking with an increased risk of HPV infection. Our results emphasize the importance of HPV vaccination programs for young women before they acquire sexual partners to prevent HR and LR HPV infections. Surveys of cervical HPV prevalence and its related risk factors increase our understanding of the natural history of this infection and establish the basis for future assessments of the impact of HPV immunization programs and the dynamics of risk factors for HPV infection in the population of Spain.

\section{Abbreviations \\ Cl: Confidence interval; HC2: Hybrid Capture II assay; HPV: Human papillomavirus; HR: High-risk; LBC: Liquid-based cytology; LR: Low-risk; POR: Prevalence odds ratio; STI: Sexually transmitted infection.}

\section{Competing interests}

The competing interest of the authors, including financial interests and relationships and affiliations relevant to the subject of the manuscript are as follows: Esther Roura has received travel grants from GlaxoSmithKline and Sanofi Pasteur MSD. Thomas Iftner has received Institutional research grants from Gen-Probe, GlaxoSmithKline, Hologic, Roche and Sanofi Pasteur MSD. José Antonio Vidart has received travel, speaker honoraria and research grants from Sanofi Pasteur MSD. Susanne Krüger Kjaer has received lecture fees, advisory board fees and institutional research grants from Sanofi Pasteur MSD and Merck \& Co. F. Xavier Bosch has received advisory board fees from Sanofi Pasteur MSD, speakers' bureaux from GlaxoSmithKline and
Sanofi Pasteur MSD and educational grants from GlaxoSmithKline and Sanofi Pasteur MSD. Nubia Muñoz has received honoraria from Merck and Sanofi Pasteur MSD as a member of Steering Committee and of Advisory board. Santiago Palacios have been a symposium speaker or advisory board member for Amgen, Arkopharma, Bayer Schering Pharma, BoehringerIngelheim Daiichi-Sankyo, Lilly, Pfizer, Roche, Sanofi Pasteur MSD, Servier and Warner Chilcott. Javier Cortes has received travel, speaker honoraria, and research grants from GlaxoSmithKline, Qiagen and Sanofi Pasteur MSD. Xavier Castellsagué has received travel and speaker honoraria and institutional research grants from GlaxoSmithKline, Merck \& Co., Inc., and Sanofi Pasteur MSD. Maria San Martin Rodriguez, Carmen Morillo, Laurence Serradell and Laurence Torcel-Pagnon are employees of Sanofi Pasteur MSD, provider of the HPV quadrivalent vaccine approved in the European Union.

\section{Acknowledgments}

This study was sponsored by Sanofi Pasteur MSD. The authors take full responsibility for the content of this contribution and thank Communigen Limited, Oxford, UK (supported by Sanofi Pasteur MSD) for their assistance in preparing the manuscript.

We would like to thank the 77 study investigators involved in the recruitment; Gabrielle Breugelmans for the study design; Perrine Bertet, Marie-Laure Kürzinger, Catherine Cohet, and Alfred Mahr for, respectively, data management, statistical analysis, and interpretation of results; France Goullet, Santiago Zas, Carlos Hortelano, Christine Lonchampt, and Sandrine Degros for study management; and Barbara Holz, Thierry Nicloux, Christophe Ronsin, and Roger Dachez for their help with the laboratory analyses. Study Group members listed at end of paper

\section{Author details}

${ }^{1}$ Cancer Epidemiology Research Program, Institut Català d'Oncologia (ICO)-IDIBELL, CIBER-ESP, RTICC, L'Hospitalet de Llobregat, Barcelona, Catalonia, Spain. ${ }^{2}$ Medical Virology, Section Experimental Virology, University Hospital of Tübingen, Tübingen, Germany. ${ }^{3}$ Gynaecology Department, Hospital Clínico San Carlos, Madrid, Spain. ${ }^{4}$ Department of Virus, Lifestyle and Genes, Danish Cancer Society Research Center, Copenhagen, Denmark. ${ }^{5}$ Department of Gynecology, Rigshospitalet, University of Copenhagen, Copenhagen, Denmark. ${ }^{6}$ Emeritus Professor at the National Cancer Institute, Bogotá, Colombia. ${ }^{7}$ Instituto Palacios, Madrid, Spain. ${ }^{8}$ Medical Department, Sanofi Pasteur MSD, Madrid, Spain. ${ }^{9}$ Epidemiology Department, Sanofi Pasteur MSD, Lyon, France. ${ }^{10}$ Senior Consultant in Gynaecology Oncology, Spanish Society of Obstetrics and Gynaecology, Palma de Mallorca, Islas Baleares, Spain.

\section{Authors' contributions}

ER was responsible for data analysis, interpretation and writing of the manuscript. TI was responsible for trial design and data analysis, collection and interpretation. JAV was responsible for data collection and interpretation. SKK was responsible for trial design. FXB was responsible for trial design and data interpretation. NM was responsible for trial design and data interpretation. SP was responsible for data interpretation. MSMR and CM were responsible for trial design. LS was responsible for trial design and data interpretation. LTP was responsible for data interpretation, JC was responsible for data interpretation. XC was responsible for study design, data analysis, interpretation and writing of the manuscript. All authors critically reviewed the manuscript and validated the final version.

\section{Members of the CLEOPATRE Spain Study Group}

The 77 study investigators:

Rafael Comino, Hospital Universitario de Puerto Real, Puerto Real, Spain José Antonio Borrego, Hospital Materno Infantil Reina Sofia, Córdoba, Spain Mónica García, Centro de Especialidades "La Bola Azul", Almería, Spain Rogelio Garrido, Consulta Privada, Sevilla, Spain

Francisco Montoya, Hospital Materno Infantil Virgen de las Nieves, Granada, Spain

José Antonio Vargas, Consulta Privada, Sevilla, Spain José Luis Cuadros, Hospital Clínico Universitario San Cecilio, Granada, Spain Blas Hervías, Hospital Universitario Puerta del Mar, Cádiz, Spain Miguel Ochando, Complejo Hospitalario Cuidad de Jaén, Jaén, Spain Antonio de Toro, Hospital San Juan de Dios, Bormujos, Spain Antonino Parrilla, Centro de Especialidades Esperanza Macarena, Sevilla, Spain 
Tomás Carrascal, Consulta Privada, Huelva, Spain

Pedro Abad, Hospital Provincial de Almería, Almería, Spain

José Manuel Ramón, Hospital de San Jorge, Huesca, Spain

María Isabel Morollón, Hospital Universitario Miguel Servet, Zaragoza, Spain

Luis González, Consulta Privada, Oviedo, Spain

Concepción Solares, Centro de Salud del Quirinal, Avilés, Spain

Javier Barrés, Policlínica Miramar, Palma de Mallorca, Spain

Gabriel Ferret, Clínica Miramar, Palma de Mallorca, Spain

Orlando Falcón, Instituto Falcón Vizcaíno, Las Palmas, Spain

Lucía Almeida, Hospital Ntra Sra. De la Candelaria, Santa Cruz de Tenerife,

Spain

Juan Miguel Falcón, Clínica de obstetricia y ginecología Dr. Falcón, Telde,

Spain

José Bretones, Residencia Hospital Marqués de Valdecilla, Santander, Spain José Antonio Mínguez, Consulta Privada, Valladolid, Spain

Guadalupe Bombín, Hospital Río Carrión, Palencia, Spain

Jaime Moreno, Hospital Vírgen de la Concha, Zamora, Spain

Diana Fernández, Hospital General de Segovia, Segovia, Spain

Gaspar González, Complejo Hospitalario Universitario de Albacete, Albacete,

Spain

Carlos Zorzo, Hospital Gral. De Guadalajara, Guadalajara, Spain

Manuel Sánchez, Consulta Privada, Toledo, Spain

Montserrat Cararach, USP Institut Universitari Dexeus, Barcelona, Spain

Jordi Antoni, Hospital Teknogin, Barcelona, Spain

Pere Cavallé, Hospital Universitario Sant Joan de Reus, Tarragona, Spain

Pere Fusté, A.G. GINOCOLEGS, Barcelona, Spain

Jordi Xercavins, Hospital Universitari Vall d'Hebrón, Barcelona, Spain

Cristina Centeno, Hospital Universitari Vall d'Hebrón, Barcelona, Spain

María Eulalia Fernández, Centro de Atención Primaria Ramona Vía, El Prat de Llobregat, Spain

Aureli Torné, Hospital Clinic i Provincial, Barcelona, Spain

Luis Puig, Consulta Privada, Barcelona, Spain

Ramón Carreras, Hospital Mare de Deu del Mar, Barcelona, Spain

Joan Meléndez, Meléndez Ginecológica SC, Blanes, Spain

Juan Carlos Martínez, Centro de Salud S. Vicente del Raspeig, Alicante, Spain

Ana de Gonzalo, Centro de Especialidades Monteolivete, Valencia, Spain

Ana Boldo, Hospital La Plana, Villareal, Spain

Alberto Romeu, Centro de Salud de Godella, Godella, Spain

José Antonio López, Consulta Ginecológica, Alicante, Spain

Mar Sanz, Centro de Planificación Familiar "El Carmen", Manises, Spain

José María Galán, Hospital Gral. San Pedro de Alcántara, Cáceres, Spain

Francisco Solano, Hospital Materno-Infantil Perpetuo Socorro, Badajoz, Spain

Alejandro Novo, H. C. U. de Santiago de Compostela, Santiago de

Compostela, Spain

José Luis Gómez, H. Materno-Infantil Teresa Herrera, La Coruña, Spain

Concepción Moreno, Centro de Orientación Familiar del Ferrol, Ferrol, Spain

Angel de la Orden, Hospital Do Meixoeiro, Vigo, Spain

Francisco Vázquez, Clínica Ginecológica CEOGA, Lugo, Spain

Pilar Miranda, Hospital de Fuenlabrada, Fuenlabrada, Spain

Pilar Benavides, Hospital Universitario Santa Cristina, Madrid, Spain

Emilia de Dios, Centro de Salud Dos de Mayo, Móstoles, Spain

José Manuel Hernández, Hospital 12 de Octubre, Madrid, Spain

José Miguel Seoane, Hospital 12 de Octubre, Madrid, Spain

Miguel Angel Huertas, Hospital Universitario de Getafe, Getafe, Spain

Mónica García, Fundación Hospital de Alcorcón, Alcorcón, Spain

Juan Ordás, Centro de Especialidades José Marvá, Madrid, Spain

Dolores Rubio, Hospital Ramón y Cajal, Madrid, Spain

Esperanza Díaz, Hospital Ramón y Cajal, Madrid, Spain

Juan Carlos Recio, Centro de Salud Andrés Mellado, Madrid, Spain

Álvaro Zapico, OBS-GYN S.L., Murcia, Spain

José Ramón Rodriquez, Consulta Privada, Murcia, Spain

José Ramón Rodriguez, Hospital Los Arcos, Santiago de la Ribera, Spain

Juan Carlos Muruzábal, Instituto Navarro de Ginecología, Pamplona, Spain

Daniel Andía, Hospital de Basurto, Bilbao, Spain

Enrique Izaguirre, Hospital Txagorritxu, Vitoria, Spain

Borja Rivero, Consulta Privada, Zarauz, Spain

José Ramón Serrano, Clínica San Martín Osasunaegía, Berbara, Spain

Esteban Campeny, Consulta Privada, Logroño, Spain

Received: 13 February 2012 Accepted: 26 June 2012

Published: 26 June 2012

\section{References}

1. Walboomers JM, Jacobs MV, Manos MM, Bosch FX, Kummer JA, Shah KV, Snijders PJ, Peto J, Meijer CJ, Muñoz N: Human papillomavirus is a necessary cause of invasive cervical cancer worldwide. J Pathol 1999, 189 (1):12-19.

2. Parkin DM, Bray F: Chapter 2: The burden of HPV-related cancers. Vaccine 2006, 24(Suppl 3):S3-11-S3-25.

3. Baseman JG, Koutsky LA: The epidemiology of human papillomavirus infections. J Clin Virol 2005, 32(Suppl 1):S16-S24.

4. Munoz N, Bosch FX, de Sanjose S, Herrero R, Castellsague X, Shah KV, Snijders PJ, Meijer CJ, International Agency for Research on Cancer Multicenter Cervical Cancer Study Group: Epidemiologic classification of human papillomavirus types associated with cervical cancer. N Engl J Med 2003, 348(6):518-527.

5. de Sanjose S, Diaz M, Castellsague X, Clifford G, Bruni L, Munoz N, Bosch FX: Worldwide prevalence and genotype distribution of cervical human papillomavirus DNA in women with normal cytology: a meta-analysis. Lancet Infect Dis 2007, 7(7):453-459.

6. Bruni L, Diaz M, Castellsague X, Ferrer E, Bosch FX, de Sanjose S: Cervical human papillomavirus prevalence in 5 continents: meta-analysis of 1 million women with normal cytological findings. J Infect Dis 2010, 202 (12):1789-1799.

7. Vaccarella S, Franceschi S, Herrero R, Munoz N, Snijders PJ, Clifford GM, Smith JS, Lazcano-Ponce E, Sukvirach S, Shin HR, de Sanjosé S, Molano M, Matos E, Ferreccio C, Anh PT, Thomas JO, Meijer CJ, IARC HPV Prevalence Surveys Study Group: Sexual behavior, condom use, and human papillomavirus: pooled analysis of the IARC human papillomavirus prevalence surveys. Cancer Epidemiol Biomarkers Prev 2006, 15(2):326-333.

8. Vaccarella S, Herrero R, Snijders PJ, Dai M, Thomas JO, Hieu NT, Ferreccio C, Matos E, Posso H, de Sanjosé S, Shin HR, Sukvirach S, Lazcano-Ponce E, Muñoz N, Meijer CJ, Franceschi S, IARC HPV Prevalence Surveys (IHPS) Study Group: Smoking and human papillomavirus infection: pooled analysis of the International Agency for Research on Cancer HPV Prevalence Surveys. Int J Epidemiol 2008, 37(3):536-546.

9. Vaccarella S, Herrero R, Dai M, Snijders PJ, Meijer CJ, Thomas JO, Hoang Anh PT, Ferreccio C, Matos E, Posso H, de Sanjosé S, Shin HR, Sukvirach S, Lazcano-Ponce E, Ronco G, Rajkumar R, Qiao YL, Muñoz N, Franceschi S: Reproductive factors, oral contraceptive use, and human papillomavirus infection: pooled analysis of the IARC HPV prevalence surveys. Cancer Epidemiol Biomarkers Prev 2006, 15(11):2148-2153.

10. Herrero R, Castle PE, Schiffman M, Bratti MC, Hildesheim A, Morales J, Alfaro M, Sherman ME, Wacholder S, Chen S, Rodriguez AC, Burk RD: Epidemiologic profile of type-specific human papillomavirus infection and cervical neoplasia in Guanacaste, Costa Rica. J Infect Dis 2005, 191 (11):1796-1807.

11. Winer RL, Hughes JP, Feng Q, O'Reilly S, Kiviat NB, Holmes KK, Koutsky LA: Condom use and the risk of genital human papillomavirus infection in young women. N Engl J Med 2006, 354(25):2645-2654.

12. Castellsagué X, Iftner T, Roura E, Vidart JA, Kjaer SK, Bosch FX, Muñoz N, Palacios S, Rodriguez MS, Serradell L, Torcel-Pagnon L, Cortes J, CLEOPATRE Spain Study Group: Prevalence and genotype distribution of human papillomavirus infection of the cervix in Spain: The CLEOPATRE study. $J$ Med Virol 2012, 84(6):947-956.

13. de Sanjose S, Almirall R, Lloveras B, Font R, Diaz M, Munoz N, et al: Cervical human papillomavirus infection in the female population in Barcelona, Spain. Sex Transm Dis 2003, 30(10):788-793.

14. Iftner T, Villa LL: Chapter 12: Human papillomavirus technologies. J Natl Cancer Inst Monogr 2003, 31:80-88.

15. Kahn JA, Rosenthal SL, Succop PA, Ho GY, Burk RD: Mediators of the association between age of first sexual intercourse and subsequent human papillomavirus infection. Pediatrics 2002, 109(1):E5.

16. Burchell AN, Winer RL, de Sanjose S, Franco EL: Chapter 6: Epidemiology and transmission dynamics of genital HPV infection. Vaccine 2006, 24 (Suppl 3):S3-52-S3-61.

17. Almonte M, Albero G, Molano M, Carcamo C, Garcia PJ, Perez G: Risk factors for human papillomavirus exposure and co-factors for cervical cancer in Latin America and the Caribbean. Vaccine 2008, 26(Suppl 11):L16-L36.

18. Gonzalez C, Ortiz M, Canals J, Munoz L, Jarrin I, de la Hera MG, García-Saiz A, del Amo J: Higher prevalence of human papillomavirus infection in migrant women from Latin America in Spain. Sex Transm Infect 2006, 82 (3):260-262. 
19. Poppe WA, Ide PS, Drijkoningen MP, Lauweryns JM, Van Assche FA: Tobacco smoking impairs the local immunosurveillance in the uterine cervix. An immunohistochemical study. Gynecol Obstet Invest 1995, 39 (1):34-38.

20. Poppe WA, Peeters R, Drijkoningen M, Ide PS, Daenens P, Lauweryns JM, Van Assche FA: Cervical cotinine and macrophage-Langerhans cell density in the normal human uterine cervix. Gynecol Obstet Invest 1996, 41(4):253-259.

21. Castellsague X, Bosch FX, Munoz N, Meijer CJ, Shah KV, de Sanjose S, ElufNeto J, Ngelangel CA, Chichareon S, Smith JS, Herrero R, Moreno V, Franceschi S, International Agency for Research on Cancer Multicenter Cervical Cancer Study Group: Male circumcision, penile human papillomavirus infection, and cervical cancer in female partners. N Eng/ J Med 2002, 346(15):1105-1112.

22. Bosch FX, Albero G, Castellsague X: Male circumcision, human papillomavirus and cervical cancer: from evidence to intervention. $J$ Fam Plann Reprod Health Care 2009, 35(1):5-7.

23. Peyton CL, Schiffman M, Lorincz AT, Hunt WC, Mielzynska I, Bratti C, Eaton S, Hildesheim A, Morera LA, Rodriguez AC, Herrero R, Sherman ME, Wheeler CM: Comparison of PCR- and hybrid capture-based human papillomavirus detection systems using multiple cervical specimen collection strategies. J Clin Microbiol 1998, 36(11):3248-3254.

24. Peyton CL, Gravitt PE, Hunt WC, Hundley RS, Zhao M, Apple RJ, Wheeler CM: Determinants of genital human papillomavirus detection in a US population. J Infect Dis 2001, 183(11):1554-1564.

25. Vernon SD, Unger ER, Williams D: Comparison of human papillomavirus detection and typing by cycle sequencing, line blotting, and hybrid capture. J Clin Microbiol 2000, 38(2):651-655.

doi:10.1186/1471-2334-12-145

Cite this article as: Roura et al:: Predictors of human papillomavirus infection in women undergoing routine cervical cancer screening in Spain: the CLEOPATRE study. BMC Infectious Diseases 2012 12:145.

\section{Submit your next manuscript to BioMed Central and take full advantage of:}

- Convenient online submission

- Thorough peer review

- No space constraints or color figure charges

- Immediate publication on acceptance

- Inclusion in PubMed, CAS, Scopus and Google Scholar

- Research which is freely available for redistribution 